\title{
Weryfikacja jakości połączeń lutowanych z miedzi za pomocą badań rentgenowskich
}

\author{
Verification of the quality of brazed joints \\ in copper by means of $\mathrm{X}$-ray examinations
}

\section{Streszczenie}

W pracy przedstawiono zagadnienia związane z oceną jakości połączeń lutowanych stosowanych w instalacjach grzewczych. Porównano ocenę jakości na podstawie badań wizualnych oraz metalograficznych z wynikami badań radiologicznych. Badania wykazały, że zastosowanie dodatkowego topnika przy lutowaniu lutem Cu-P poprawia zwilżalność powierzchni lutowanej, tym niemniej samotopnikujące działanie lutu było wystarczające dla uzyskania wymaganego poziomu jakości złączy.

Słowa kluczowe: lutowanie twarde; lutowanie miedzi; badania złączy lutowanych; jakość połączeń; badania radiologiczne; tomograf komputerowy

\section{Abstract}

The paper presents issues related to the assessment of the quality of brazed joints used in heating systems. The quality of joints assessed on the basis of visual and metallographic tests were compared with radiological examinations. Studies have shown that the use of chemical flux by soldering with Cu-P solder improves wettability soldered surface, however self-fluxing action of the solder was sufficient to obtain the required level of quality of joints.

Keywords: brazing; soldering copper; soldered joints testing; quality of joints; X-ray analysis; CT scanner

\section{Wstęp}

Luty samotopnikujące miedziano-fosforowe należą do jednych z najczęściej stosowanych spoiw lutowniczych w przemyśle i stanowią ok. $22 \%$ stosowanych wszystkich lutów twardych [1]. Fosfor zawarty w lutach CuP skutecznie redukuje tlenki miedzi i nie ma w zasadzie konieczności stosowania dodatkowo topników chemicznych dla poprawy zwilżalności. Dodatkowo poprawę zwilżalności miedzi przez luty tego typu można uzyskać na drodze wymuszonych drgań mechanicznych [2].

W niektórych przypadkach ilość tworzących się tlenków na powierzchni miedzi może okazać się za duża dla ich redukcji tylko przez fosfor zawarty w lucie i wówczas wspomaga się proces lutowania dodatkowymi topnikami. Np. podczas lutowania płomieniowego złącza rurowego, redukujące działanie płomienia ogranicza się do zewnętrznej powierzchni złącza natomiast nagrzane powierzchnie wewnętrzne złącza, mające kontakt z powietrzem, będą ulegać intensywnemu utlenianiu, co może wpływać na szybkość i skuteczność redukcji tlenków w szczelinie lutowniczej. Duży wpływ na to mają parametry technologiczne lutowania, jak czystość początkowa powierzchni, czy szybkość i czas nagrzewania. Okazuje się, że podawanie azotu do wnętrza rurki podczas lutowania skutecznie chroni powierzchnię miedzianą rurki od utleniania i poprawia zwilżalność lutem [3].
Podstawowym kryterium kwalifikacji w ocenie jakości połączeń lutowanych lutami twardymi jest stopień wypełnienia złącza zakładkowego lutem. Istnieją jednak dwa różne podejścia do jego określenia. Jedno, zawarte w dokumencie Niemieckiego Instytutu Miedzi [4] określa stopień wypełnienia złącza ze stosunku sumy długości niezgodności występujących na tzw. „drodze krytycznej” do długości konstrukcyjnej złącza. Za poprawne uważa się złącze lutowane, dla którego obliczony współczynnik wypełnienia wynosi co najmniej $80 \%$.

Inaczej ocenę jakości złączy lutowanych proponuje się w PN-EN ISO 18279 [5], w której ustalono trzy poziomy jakości B, C i D ( na wzór poziomów jakości dla złączy spawanych). Granice niezgodności dla ustalonych poziomów jakości B, C i D proponowane w tej normie oparte są na rzutowaniu powierzchni niezgodności na powierzchnię złącza. $Z$ tego powodu, bardzo pomocne w ocenie jakości złączy według tej normy są nowoczesne metody radiograficzne, np. rentgenowska tomografia komputerowa, w której zaawansowane oprogramowanie obróbki obrazu radiogramu w sposób istotny ułatwia wykrycie rozmieszczenia niezgodności i może automatyzować ich pomiary oraz wykonywać odpowiednie obliczenia.

Badania takie zastosowano do oceny jakości złączy rurowych z miedzi, wykorzystując przy tym wspomniane zalety tomografii materiałowej.

Prof. dr hab. inż. Andrzej Ambroziak; dr inż. Piotr Białucki; dr inż. Wiesław Derlukiewicz; dr inż. Artur Lange - Politechnika Wrocławska; inż. Jan Chmielewski - Viessmann Technika Grzewcza Sp. z o.o., Legnica.

Autor korespondencyjny/Corresponding author. piotr.bialucki@pwr.edu.pl 


\section{Przedmiot pracy}

Przedmiotem badań były złącza lutowane rurek miedzianych stosowanych w instalacjach grzewczych. Badano połączenia kielichowe oraz teowe. Wygląd złączy bezpośrednio po lutowaniu przedstawiono na rysunku 1, na którym widać, że złącza lutowane bez topnika mają powierzchnię wyraźnie czystszą niż te lutowane z dodatkiem topnika.

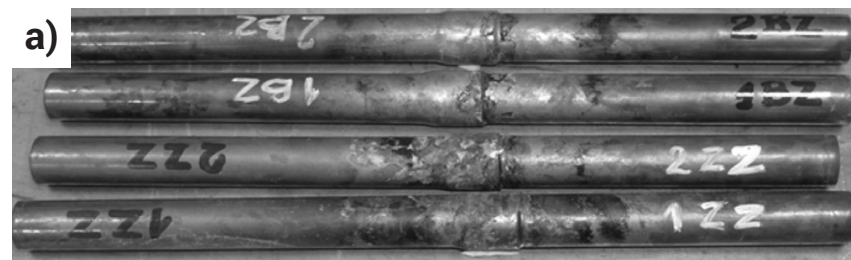

\section{b)}

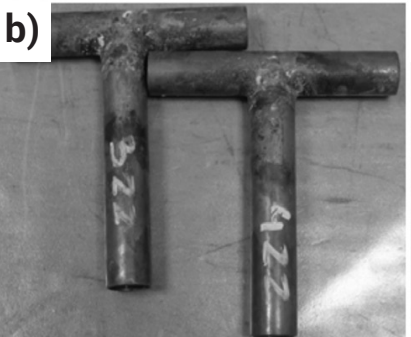

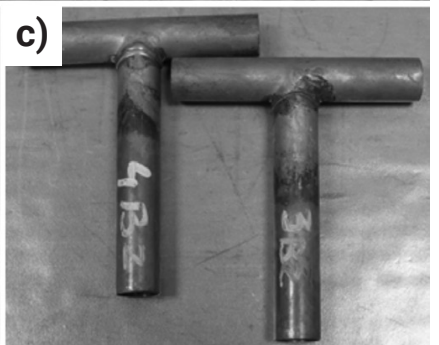

Rys. 1. Badane złącza lutowane rurek miedzianych; a) złącza kielichowe, b) i c) złącza teowe; BZ - lutowane bez topnika, ZZ - lutowane $z$ topnikiem

Fig. 1. The examined brazed joints of copper tubes; a) socket joints, b) and c) T-joints; BZ - brazed without flux, ZZ - brazed with flux

Rurki wykonane z miedzi gat. R250 (wg PN-EN 1057 [6]) lutowano lutem twardym miedziano-fosforowym z dodatkiem cyny gat. CuP386 (wg PN-EN ISO 3677 [7]) bez topnika oraz z dodatkiem topnika. Próbki przed lutowaniem były myte w myjce ultradźwiękowej.

Jednym z celów badań było sprawdzenie wpływu obecności topnika na jakość otrzymywanych złączy lutowanych lutem samotopnikującymCuP7Sn7. Kryterium oceny było osiągnięcie poziomu jakości C wg PN-EN ISO 18279 [5].

\section{Badania wizualne}

Przed dokonaniem oceny wizualnej próbki lutowane oczyszczono z resztek topnika. Wygląd próbek przygotowanych do badań pokazano na rysunku 2. Tak przygotowane próbki poddano także badaniom na tomografie komputerowym.
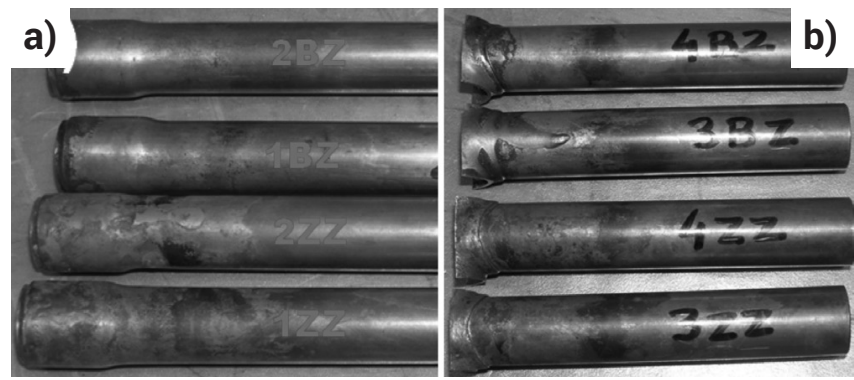

Rys. 2. Wygląd próbek przygotowanych do badań wizualnych i radiologicznych; a) złącza kielichowe; b) złącza teowe

Fig. 2. Appearance of samples prepared for visual tests and X-ray analysis; a) socket joints; b) T-joints

Badania wizualne złączy kielichowych wykazały prawidłowy kształt lutowiny w miejscu szczeliny (rys. 2a) zarówno na próbkach ZZ (lutowanych z topnikiem) oraz BZ (lutowanych bez topnika). Na powierzchni rurek widać nadmier- ne rozpłynięcie lutu (niezgodność 7QAAA wg PN-EN-ISO 18279), które nie ma wpływu na funkcjonowanie złączy i zgodnie z normą może nie być brane pod uwagę przy ocenie poziomu ich jakości.

$\mathrm{Na}$ podstawie oględzin zewnętrznej powierzchni badanych złączy rurek nie można stwierdzić jednoznacznie czy spełnia ona wymagania poziomu jakości $C$ ze względu na niezgodności, np. niedolutowania, które mogą wystąpić na niewidocznej stronie wewnętrznej rurki.

Badania wizualne złączy teowych od strony wewnętrznej rury wykazały istotne różnice $w$ wyglądzie szczeliny między złączami ZZ i BZ, co pokazano na rysunku 3.
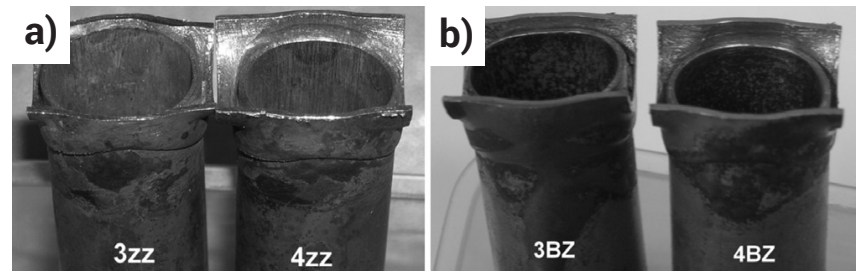

Rys. 3. Widok złączy lutowanych teowych od strony wewnętrzne Fig. 3. View of brazed T-joints on the inside

W złączach lutowanych $3 Z Z$ i $4 Z Z$ występuje lutowina z wyraźną wypływką na całym obwodzie rurki (rys. 3a), natomiast w złączach 3BZ i 4BZ takie wypływki widać (rys. 3b), co wskazuje na to, że lut nie wypełnił szczeliny na całej długości zakładki.

\section{Analiza składu chemicznego}

Skład chemiczny lutowiny wykonany w punkcie zaznaczonym na rysunku $4 a$, określono za pomocą systemu mikroanalizy rentgenowskiej EDX (Spektrometr dyspersji energii promieniowania rentgenowskiego), zamontowanego na skaningowym mikroskopie elektronowym. Wynik analizy przedstawiono na rysunku 4b w postaci widma promieniowania ze spektrometru EDX. Piki na widmie zarejestrowanego promieniowania są automatycznie oznaczane symbolem pierwiastka, któremu dany pik odpowiada.

Wyniki analizy przedstawione na rysunku 4 potwierdziły, że do łączenia rurek miedzianych użyto lutu Cu-P, w którym dodatkowym pierwiastkiem modyfikującym jest cyna występująca w zbliżonej ilości do zawartości fosforu.
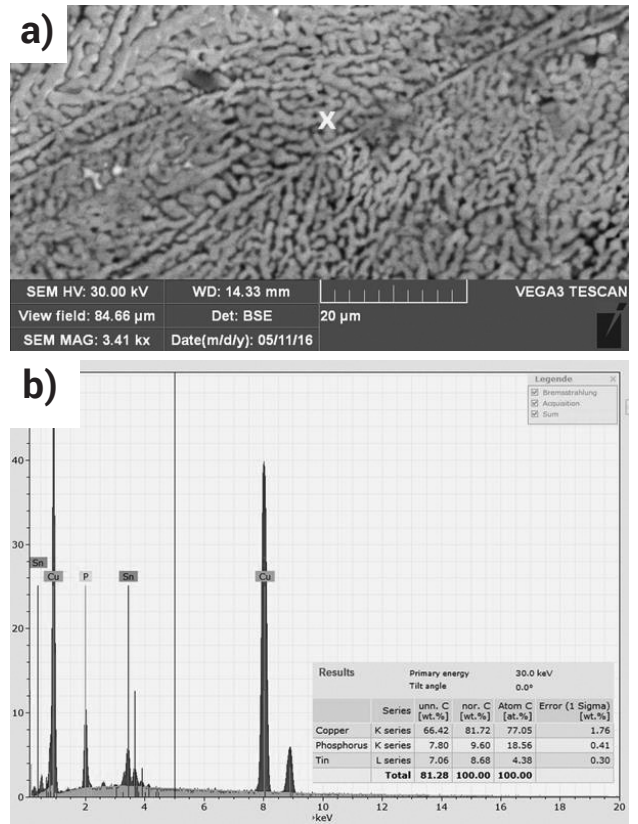

Rys. 4. Analiza EDX lutowiny na próbce $3 Z Z$

Fig. 4. Analysis EDX of brazed $3 Z Z$ sample 


\section{Badania metalograficzne}

Badania metalograficzne przeprowadzone na zgładach podłużnych złączy lutowanych wykazały wyraźne różnice w budowie złączy lutowanych bez topnika i z topnikiem (rys. 5 i 6). Widać wyraźnie, że zastosowanie topnika wpływa korzystnie na wypełnienie szczeliny lutem (rys. 6) i dotyczy to zarówno złączy kielichowych jak i teowych.

Wielkość zakładki w złączu teowym wynosi $4 \mathrm{~mm}$. Widoczna na rysunku 5 wielkość niedolutowania wynosi $1 \div 1,5 \mathrm{~mm}$.

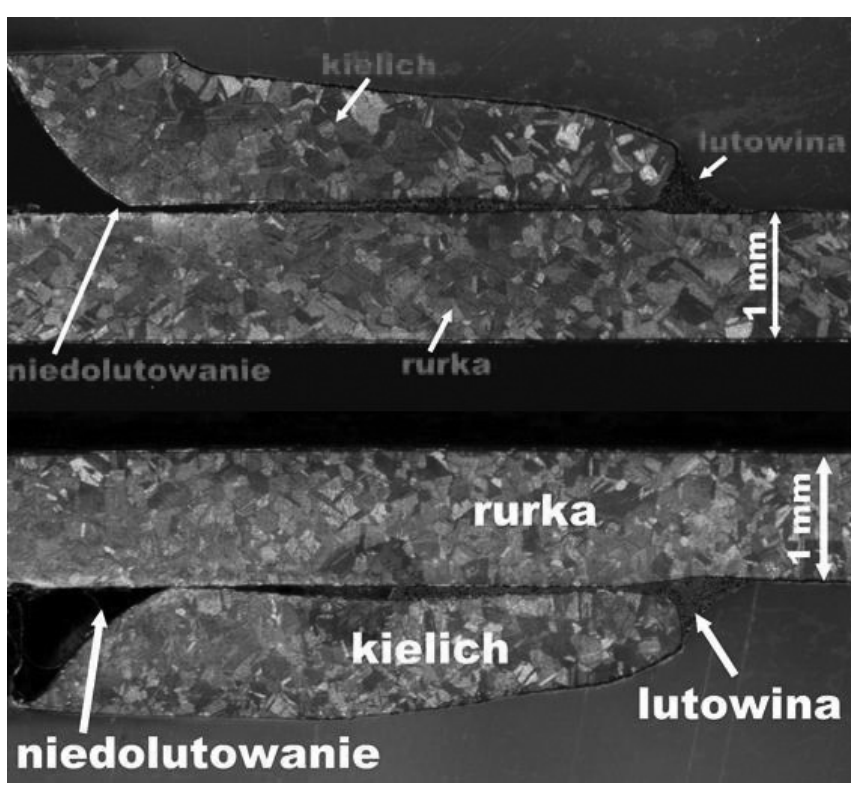

Rys. 5. Makrofotografia złącza teowego 3BZ lutowanego bez topnika. Trawiono $10 \%$ nadsiarczanem amonu.

Fig. 5. Macro T-joint of $3 Z Z$ sample soldered without flux. It was etched with $10 \%$ ammonium persulfate.

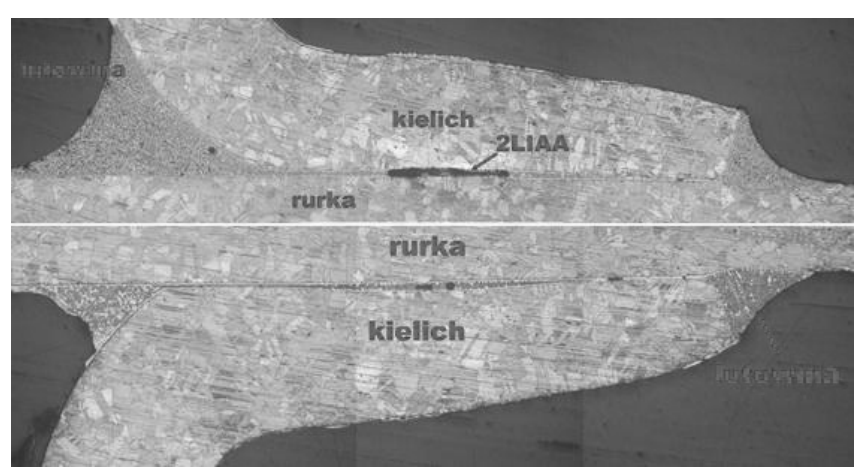

Rys. 6. Makrofotografia złącza teowego $3 Z Z$ lutowanego z topnikiem. Trawiono $10 \%$ nadsiarczanem amonu.

Fig. 6. Macro T-joint of $3 Z Z$ sample soldered with flux. It was etched with $10 \%$ ammonium persulfate.

\section{Badania radiologiczne}

Próbki do badań na tomografie komputerowym zostały przycięte w sposób pokazany na rysunku 2 celem ułatwienia uzyskania bardziej czytelnego obrazu radiogramu i umożliwienia odpowiedniego mocowania w obrotowym stoliku oprzyrządowania tomografu.

Prześwietlenia badanych złączy wykonano na rentgenowskim tomografie komputerowym METROTOM 1500 w technice rekonstrukcji otrzymując pełny obraz przestrzenny 3D każdego złącza.

Zasady działania tomografów komputerowych i tworzenia rekonstrukcji przestrzennego obrazu badanego obiektu można znaleźć w literaturze [8,9], a przykłady praktycznego zastosowania tomografii komputerowej do badań jakości połączeń spajanych przedstawiono

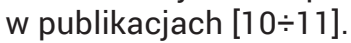

Do analizy jakości badanych złączy lutowanych wykorzystano oprogramowanie VGStudio Max, które umożliwia wykrycie położenia wad a także ich ilościową analizę w postaci wymiarów liniowych, powierzchni oraz zajmowanej przez nie objętości. Program ten, służący do obróbki wyników badań, umożliwia w czytelny sposób graficzne przedstawienie rozmieszczenia defektów występujących w złączach, pokazując je w różnych barwach zależnie od ich wielkości.

Na rysunku 7 pokazano przykładowe obrazy przestrzenne badanych złączy z wadami odwzorowanymi w różnych kolorach zależnie od ich wielkości, którą można orientacyjnie odczytać na podziałce pionowej.
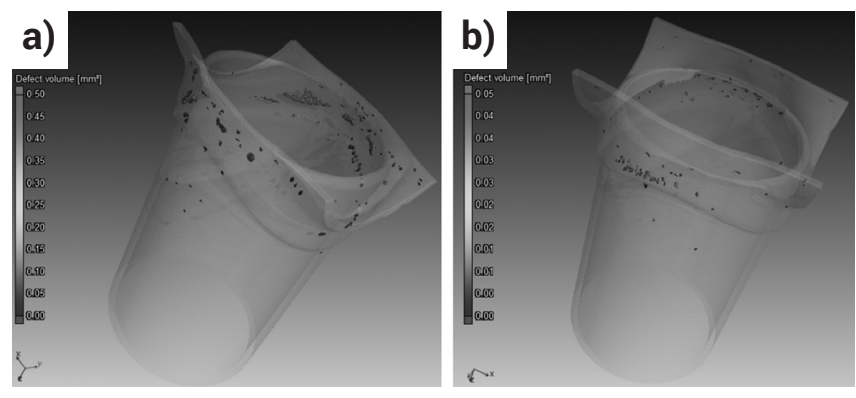

Rys. 7. Radiogramy teowych złączy lutowanych rur miedzianych; a) z topnikiem, b) bez topnika

Fig. 7. X-ray Image of brazed T-joint of copper pipes; a) with flux, b) without flux

$\mathrm{Na}$ podstawie wyników analizy ilościowej powierzchni zajmowanych przez niezgodności w złączach w stosunku do powierzchni zakładki złączy określono stopień ich wypełnienia lutem. Wyników analizy przedstawiono w tablicy I.

\section{Podsumowanie}

Wyniki oceny stopnia wypełnienia badanych złączy lutem, wykonane w oparciu o badania radiologiczne przedstawiono w tablicy I. Jako miarę wypełnienia złączy przyjęto stosunek powierzchni rzutu niezgodności do powierzchni rozwiniętej złącza o długości zakładki $10 \mathrm{~mm}$ w przypadku złączy kielichowych oraz zakładki $4 \mathrm{~mm}$ w przypadku złączy teowych.

Badania wykazały, że zastosowanie dodatkowego topnika przy lutowaniu płomieniowym miedzi lutem samotopnikującym wyraźnie poprawia zwilżalność lutowanej powierzchni rurek, ułatwiając wypełnienie szczeliny na całej długości zakładki i utworzenie poprawnego menisku wklęsłego lutowia po obu jej stronach. Tym niemniej wymagany poziom jakości złączy C został osiągnięty również w złączach lutowanych bez dodatkowego topnika, co ma duże znaczenie ekonomiczne oraz praktyczne z uwagi na znaczne uproszczenie procesu lutowania. 
Tablica I. Wyniki oceny stopnia wypełnienia badanych złączy lutowanych (wg normy PN-EN ISO 18279:2003 przy założeniu wymaganego poziomu jakości C)

Table I. The results of the assessment of the degree of filling of respondents brazed joints (acc. PN-EN ISO 18279: 2003, assuming the required level of quality $\mathrm{C}$ )

\begin{tabular}{|c|c|c|c|c|c|c|}
\hline $\begin{array}{l}\text { Rodzaj } \\
\text { złącza }\end{array}$ & $\begin{array}{c}\mathrm{Nr} \\
\text { próbki }\end{array}$ & $\begin{array}{l}\text { Długość } \\
\text { zakładki }\end{array}$ & $\begin{array}{c}\text { Powierzchnia } \\
\text { badana złącza } \\
{\left[\mathrm{mm}^{2}\right]}\end{array}$ & $\begin{array}{c}\text { Rodzaje } \\
\text { występujących } \\
\text { niezgodności } \\
\end{array}$ & $\begin{array}{l}\text { Powierzchnia złącza } \\
\text { zajmowana przez } \\
\text { niezgodność, }\left[\mathrm{mm}^{2}\right]\end{array}$ & $\begin{array}{c}\text { Stopień } \\
\text { wypełnienia } \\
{[\%]} \\
\end{array}$ \\
\hline \multirow{2}{*}{ kielichowe } & \multirow{2}{*}{$1 \mathrm{BZ}$} & \multirow{2}{*}{$10 \mathrm{~mm}$} & \multirow{2}{*}{565} & \multirow{2}{*}{$\begin{array}{r}\text { 2LIAA } \\
2 \text { BGAA }\end{array}$} & 15,6 & \multirow{2}{*}{79,5} \\
\hline & & & & & 4,9 & \\
\hline \multirow{2}{*}{ kielichowe } & \multirow{2}{*}{$1 Z Z$} & \multirow{2}{*}{$10 \mathrm{~mm}$} & \multirow{2}{*}{565} & \multirow{2}{*}{$\begin{array}{r}\text { 2LIAA } \\
\text { 2BGAA }\end{array}$} & 9,5 & \multirow{2}{*}{87,2} \\
\hline & & & & & 3,3 & \\
\hline \multirow{2}{*}{ kielichowe } & \multirow{2}{*}{$2 \mathrm{BZ}$} & \multirow{2}{*}{10 mm } & \multirow{2}{*}{565} & \multirow{2}{*}{$\begin{array}{r}2 \mathrm{LIAA} \\
2 \mathrm{BGAA}\end{array}$} & 22,7 & \multirow{2}{*}{73,1} \\
\hline & & & & & 4,2 & \\
\hline \multirow{2}{*}{ kielichowe } & \multirow{2}{*}{$2 Z Z$} & \multirow{2}{*}{10 mm } & \multirow{2}{*}{565} & \multirow{2}{*}{$\begin{array}{r}\text { 2LIAA } \\
\text { 2BGAA }\end{array}$} & 13,2 & \multirow{2}{*}{83,2} \\
\hline & & & & & 3,6 & \\
\hline \multirow{3}{*}{ teowe } & \multirow{3}{*}{$3 B Z$} & \multirow{3}{*}{$4 \mathrm{~mm}$} & \multirow{3}{*}{113} & \multirow{3}{*}{$\begin{array}{l}\text { 2LIAA } \\
\text { 2BGAA } \\
\text { 4CAAA }\end{array}$} & 2,9 & \multirow{3}{*}{81,9} \\
\hline & & & & & 15,2 & \\
\hline & & & & & $\left.{ }^{*}\right)$ & \\
\hline \multirow{2}{*}{ teowe } & \multirow{2}{*}{$3 Z Z$} & \multirow{2}{*}{$4 \mathrm{~mm}$} & \multirow{2}{*}{113} & \multirow{2}{*}{$\begin{array}{r}\text { 2LIAA } \\
\text { 2BGAA }\end{array}$} & 9,4 & \multirow{2}{*}{79,6} \\
\hline & & & & & 11,0 & \\
\hline \multirow{2}{*}{ teowe } & & & & 2BGAA & 7,4 & \\
\hline & 4BL & $4 \mathrm{~mm}$ & 113 & 4CAAA & *) & 92,6 \\
\hline & & & & 2LIAA & 10,7 & 84,1 \\
\hline teowe & $4 Z Z$ & $4 \mathrm{~mm}$ & 113 & 2BGAA & 5,2 & \\
\hline
\end{tabular}

\section{Wnioski}

Na podstawie przeprowadzonych badań można wyciągnąć następujące wnioski:

- Ocena jakości złączy lutowanych oparta jedynie na badanych wizualnych może okazać się niewystarczająca (np. w połączeniach rurowych).

- Badania metalograficzne, które często uzupełniają badania wizualne, pozwalają na ocenę złączy od strony wewnętrznej rury, jednak nie dają możliwości pełnej oceny wielkości i rozkładu niezgodności wewnątrz całego złącza.

- Badania radiologiczne dają największe możliwości przeprowadzenia oceny jakości połączeń lutowanych.

- Na podstawie przeprowadzonych badań wykazano, że powierzchnie niezgodności występujące w badanych złączach zajmują mniej niż 30\% powierzchni złącza, zatem zarówno badane złącza kielichowe i teowe spełniają wymagania poziomu jakości C wg PN-EN ISO 18279:2003. Poziom ten został osiągnięty zarówno w złączach lutowanych z użyciem dodatkowego topnika jak i lutowanych bez niego.

\section{Literatura}

[1] Mirski Z., T. Piwowarczyk. Analiza aktualnego stanu rozwoju technologii lutowania w Polsce. Przegląd Spawalnictwa 2010, nr 11, s. 3-9.

[2] Bąkała M., Wpływ drgań niskiej częstotliwości na zwilżalność podłoża w procesie spajania materiałów przez lutowanie. Przegląd Spawalnictwa 2010, nr 10, s. 23-26.

[3] Poradnik f-my HARRIS. Lutowanie twarde i miękkie.

[4] Beurteilung von Hartlötverbindungen an Kupferrohren. DKI Werkstoff Prüfblatt Nr. 811. 1982r.

[5] PN-EN ISO 18279: 2008. Lutowanie twarde - Niezgodności w złączach lutowanych na twardo.

[6] PN-EN 1057+A1:2010. Miedź i stopy miedzi -- Rury miedziane okrągłe bez szwu do wody i gazu stosowane w instalacjach sanitarnych i ogrzewania.

[7] PN-EN ISO 17672: 2010. Lutowanie twarde - Spoiwa.

[8] Ratajczyk E.: Rentgenowska tomografia komputerowa (CT) do zadań przemysłowych. Pomiary automatyka Robotyka 5/2012, s. 104-113.

[9] Heljak M., Jaroszewicz J., Święszkowski W., Krzysztof J. Kurzydłowski K. J.: Mikrotomografia rentgenowska jako metoda obrazowania w inżynierii materiałowej. Serwis internetowy poświęcony badaniom nieniszczącym. Serwis HYPERLINK www.badania-nieniszczace.info/ Badania-Nieniszczace-Nr-01-08-2009/Serwis-Badania-Nieniszczace-0108-2009-Zawartosc.html Nr 01/08/2009.

[10] Kułaszka A., Chalimoniuk M., Wieczorowski M., Brzozowski D.: Ocena wad i niezgodności spawalniczych metodą tomografii komputerowej CT, Przegląd Spawalnictwa 2015, nr 12.

[11] Jóźwik J., Dziedzic K., Wierzba W.: Mikrotomograficzna identyfikacja wad powłok napawanych, Przegląd Spawalnictwa 2016, nr 7. 